\title{
Applying a Bayesian Network methodology to an offshore gas turbine driven power generator to demonstrate the cause and effect relationship of the turbine running over- speed and the associated switchboard failures.
}

\author{
S. Loughney \\ Faculty of Engineering and Technology, Liverpool John Moores University, Liverpool, UK, \\ s.loughney@ljmu.ac.uk. \\ J. Wang \\ Faculty of Engineering and Technology, Liverpool John Moores University, Liverpool, UK, j.wang@ljmu.ac.uk. \\ D. B. Matellini \\ Faculty of Engineering and Technology, Liverpool John Moores University, Liverpool, UK, \\ d.b.matellini@ljmu.ac.uk.
}

\begin{abstract}
This paper investigates the benefits of applying a Bayesian Network in quantitative risk assessment of the integrity of an offshore gas turbine driven generator. The focus of the research is based on the potential failures and incidents associated with an offshore gas turbine running overspeed and failures within the switchboard. The potential consequences that follow said failures, such as fire, explosion and damage to mechanical equipment are also factored into the analysis. A methodology is outlined in order to construct a coherent BN model. This methodology consists of several steps, starting with identifying variables, to then constructing a qualitative $\mathrm{BN}$ model from these variables. The methodology culminates in validation of the BN model. A case study, regarding individual and combined component failures is also applied to demonstrate and validate the methodology. The Bayesian network allows the cause-effect relationships to be modelled through clear graphical representation. Similarly, the model can accommodate for continual updating of failure data. Partial validity of the model is demonstrated against some benchmark axioms. It is vital to maintain that the model must remain practical and close to reality from the perspective of gathering data and generating results.
\end{abstract}

Keywords: Bayesian Networks, offshore, gas turbine, overspeed, hydrocarbon release, ignition.

\section{Introduction}

This research focuses on the continued development of Bayesian Network (BN) models, for modelling the relationship between failures and consequences of an offshore gas turbine. The intention is to model a sequence of events following a number of component failures, under certain conditions and assumptions.

Previous research has defined these initial failures as control system failures and physical or structural failures. The previous $\mathrm{BN}$ models in this research have outlined the relationships between these initial failures and potential Hydrocarbon (HC) releases and fire and explosion consequences. These BNs, along with the model presented in this paper, should provide a base with which to expand the $\mathrm{BN}$ model to facilitate the requirement of having a dynamic risk assessment model that allows for accurate representation of the hazards and consequences associated with gas turbine failures.

The research presented within this paper is an expansion of previous research conducted for an electrical generation system of an offshore installation. The initial research, conducted by Loughney \& Wang (2017), focused on creating a dynamic risk assessment model for an electrical generation system, based upon one initial component failure in the form of a rotor retaining ring failure. A sequence of events and a $\mathrm{BN}$ were produced to demonstrate the cause and effect relationships between the safety critical elements of the generator. The BN demonstrated a number of potential consequences, such as, Gas Import Riser failure and High Pressure Gas Flare Drum failure, resulting in a potential $\mathrm{HC}$ release. These final consequences were not expanded or demonstrated in detail to keep the complexity of the model as low as possible while achieving valid results. Similarly, Loughney et al. (2018) further developed a BN model that focused on gas turbine fuel gas release and the resulting ignition consequences (Loughney, et al., 2018).

This research expands on this by constructing a new $\mathrm{BN}$ network that combines the HC release scenarios of Loughney \& Wang (2017) and the ignition scenarios of Loughney et al. (2018). Gas turbine generator sets, particularly aeroderivative gas turbines, are sensitive to electrical faults that can severely damage the turbine and surrounding equipment. Hence, this new BN demonstrates the potential $\mathrm{HC}$ release consequences of an offshore gas turbine running overspeed along with the potential ignition consequences resulting from an electrical overload (Loughney \& Wang, 2017) (Loughney, et al., 2018).

\section{Background}

\subsection{Overspeed}

A gas turbine generator usually consists of three key mechanical components; the gas turbine, the gearbox and the generator. These components are all connected through couplings, which must be able to cope with any potential misalignments and displacements caused by failures in the system. A gearbox is essential in virtually all generator sets. This is because the generator will operate between 1,500 to $3,000 \mathrm{rpm}$ and the gas turbine can operate anywhere from 3,600 to $20,000 \mathrm{rpm}$. However, in this research the gas turbine operates at 3,600 rpm (RMRI Plc., 2009) (Perera, et al., 2016) (HSE, 2006).

Several events or scenarios may lead to a gas turbine running overspeed. A shaft failure may lead to the decoupling of the 
Loughney, S., Wang, J. \& Matellini, D. B.

compressor and the turbine mounted on the shaft. This decoupling can incite an event whereby the power produced by the turbine is not absorbed by the compressor. In this situation the gas expansion in the turbine does not immediately halt, as the gas is still flowing in the main gas path. This continued flow of gas, for however brief a time it exists after the failure, can cause the rotor to accelerate. This can result in severe deformation to the turbine, and the other components, if it is not restrained. This is known as a shaft overspeed event (Fetenant, et al., 2012) (Almasi, 2011).

Two types of failures most commonly lead to a shaft over-speed event; control system failures and shaft breakage. The latter can occur not as a primary cause only but late in the failure event, potentially resulting in a gas fire or explosion. However, there is a substantial difference between the failures, which can arise from the location of the speed probes in the engine. The engine control obtains measures of the speed of the shafts from probes that are located on the compressor end of the shaft. These are usually housed in the internal gearbox. If the shaft is severed behind the location of these probes, they can only read the falling speed of the compressor end of the spool, and the engine control has no notion that the turbine is running overspeed (Onsite Energy, 2013) (Pawsey, et al., 2018).

On the other hand, control system failures can be arrested by the activation of over-speed protection devices that shut down the fuel flow when the speed probes read values over a prescribed threshold. This is also possible because the engine's response to control system failures is milder and slower than to an instantaneous shaft breakage. According to Gallar (2010) the timing of shaft overspeed events are of the order of hundreds of milliseconds, whereas the control failure develops over times around tens of milliseconds. Furthermore, it is also stated by Psarra et al. (2009) that if the terminal speed attained exceeds a certain critical limit, high-energy debris may be released from the engine compromising the safety of the operations. Similarly, RMRI Plc. (2009) concur that an overspeed event can release high-energy debris and projectiles. They state that the rotor retaining rings within aeroderivative gas turbines are susceptible to stress cracking given an overspeed event. This results in increased shaft displacement and potential bearing failure. This scenario was modelled by Loughney \& Wang (2017), as previously stated. RMRI Plc. (2009) states that if the terminal speed attained exceeds a certain critical limit, high energy debris may be released from the engine compromising the safety of the operations. Given that the turbine runs at $3,600 \mathrm{rpm}$ (normal speed), the radial deflection of a rotorretaining rings is approximately $1.5 \mathrm{~mm}$, and the design of the rings allows them to withstand these stresses. However, when the turbine runs at $20 \%$ overspeed, the radial deflection becomes approximately $2.5 \mathrm{~mm}$. This is an increase of $66 \%$ on the radial deflection for normal operating speeds. Therefore, it can be said that given that a turbine runs more than $20 \%$ overspeed, the rotor retaining rings increases the risks of retaining ring failure. However, there is some contention to this statement. Brush Electrical Machines Ltd. (1999) state that "from the evidence available, there appears to be no correlation between the incidence of stress cracking and generator rating or speed". What is key is that running overspeed has a great effect on the shaft alignment and can damage components if the shaft vibrations are greater than the design tolerance. It can still be said that running overspeed does have an effect on other components of the rotor assembly, potentially exposing component stresses close to their yield strength. Therefore, it is advisable that stress analyses of components should be conducted to determine the status of components following an overspeed event, to determine whether there is an increased probability of failure (Chacartegui, et al., 2011) (HSE, 2006) (Perera, et al., 2015) (Pawsey, et al., 2018) (RMRI Plc., 2009). The failures outlined thus far are all related to the mechanical side of the gas turbine operations. However, if the pure mechanical failures are disregarded, the potential source for overspeed is the generator. Electrical fault conditions in the generator can produce over torques, which can spread backwards in the system. It is possible that these events can expose the turbine and gearbox components to excessive torque
2

and speed. There are two types of electrical fault that can cause this; mal-synchronization and short circuit at generator terminals. Both events can produce torque peaks at the generator output of ten times the full load torque. The nature and size of the torque peaks are usually known and defined by the manufacturer. These situations can be complex, as a dynamic analysis of the torque fault conditions is required in order to determine the magnitude of the torque that reaches the gas turbine.

\subsection{Overload and electrical ignition}

When designing an electrical power generator, there is a responsibility to meet code requirements to ensure that the electrical equipment is protected against destructive current flows. These current flows can produce temperatures in electrical components and wiring that are above the specified rating and design limits. The protection from is usually termed "overcurrent protection" and are caused by equipment overloads by short circuits or ground faults. These overloads occur when equipment and components are subjected to currents above their design rating, producing excessive heat. Short circuits generally occur when there is an unintentional, direct line to line connection between conductors, and can potentially generate temperatures of thousands of degrees above the stated design ratings. Similarly, ground faults occur when an electrical current flows from a conductor to some uninsulated metal, which is not design to conduct electricity in the system. These ground currents can be exceptionally hazardous to personnel and other electrical based systems in contact with the foreign metal structure or object (Boeman, 2013) (Lee, 2018). The two most common protection measures from overloads and overcurrents are fuses and circuit breakers. Fuses are the simplest form of overcurrent protection. They consist of a conducting element enclosed in a tube of non-conductive material and connected by ferules at each end. The ferules fit into slots to allow the fuse to complete a split circuit. In the event of excess current flowing through the circuit, the conducting element melts and breaks the circuit, interrupting the current flow. This means that a fuse can only be used once before it must be replaced, which is a massive disadvantage when compared to circuit breakers which can be reset (Onsite Energy, 2013).

Circuit breakers are automatically operated switches designed to protect the circuit from overload or short circuit. There are a number of circuit breaker types utilized in industry, depending on the required level of protection:

- Inverse Time Trips: These trip faster as current increases. They provide overload protection, however, they also allow equipment and conductors to briefly experience excessive loads.

- Adjustable Trips: These are used when the operation of several protection devices in a system must be coordinated. Designers place the lowest rated trips nearest to the devices being protected so that a fault in one area is isolated but allows current elsewhere in the system to continue to flow.

- Instantaneous Trips: These use only the magnetic element of the trip and provide no overload protection. Also known as motor circuit protectors, or MCPs, they normally are used to protect large motors from short circuits and ground faults.

Short circuits can produce enough thermal and electromagnetic forces to destroy any protective device. When selecting a protective device, it is vital to consider the available short circuit amperage, which is the potential amperage at any site in the system. Further consequences of this are potential electrical ignition sources (Courty \& Garo, 2017).

Ignition and burning of electrical cables are possible causes of fires in an offshore setting. Similarly, cables may also lose their functions or be less efficient when exposed to heat sources (progressive change in resistance, deterioration of the signal quality and shortcut). Electrical cables have an insulation layer which is potentially flammable and may decompose at high temperatures. In nuclear power plants, electrical wire is a major source of fire ignition, consisting of $42 \%$ of total fires (Fisher, et al., 2015). Most electrical fires are caused by short circuit, overheating and worn wire with the ignition of insulation 
Loughney, S., Wang, J. \& Matellini, D. B attached to the wires (Wang, et al., 2016). Once ignited, fires would propagate along the wire and ignite nearby combustibles, releasing heat, smoke and toxic gas.

Furthermore, arc flashes pose a particular risk in an offshore environment with lower voltage machinery with between $480 \mathrm{~V}$ and $600 \mathrm{~V}$ and medium voltage machinery of $>600 \mathrm{~V}$. This includes equipment such as switches, fuses, circuit breakers or relays. An arc flash is the light and heat produced from an electric arc supplied with sufficient electrical energy to cause substantial damage, harm, fire, or injury. These arc flashes are most commonly caused by during a fault, or short circuit condition. One of the most common causes of arc-flash injuries happens when switching on electrical circuits and, especially, tripped circuit-breakers. A tripped circuit-breaker often indicates a fault has occurred somewhere down the line from the panel. The fault must usually be isolated before switching the power on, or an arc flash can easily be generated. Small arcs usually form in switches when the contacts first touch, and can provide a place for an arc flash to develop. If the voltage is high enough, and the wires leading to the fault are large enough to allow a substantial amount of current, an arc flash can form within the panel when the breaker is turned on. According to RigZone Arc flash temperatures exceed $19,500^{\circ} \mathrm{C}$, hotter than the sun's surface, with 700 miles per hour projectile-producing pressure, which can throw a person across a room. An estimated five to 10 arc flashes occur each day in the United States, according to a report from the National Institute for Occupational Safety and Health (Boeman, 2013) (CLarck, 2018).

It is events, such as those described in Section 2 that increase the requirement for a dynamic risk assessment model to accurately monitor the consequences of failures within gas driven generators. This is due to the fact that they are critical in the survival of crew members as well as the integrity of the respective offshore installation. As stated previously and given the literature review presented, the focus is the modelling of overspeed and overload events on $\mathrm{HC}$ release and potential ignition

\section{Methodology}

Many systematic procedures in use allow for construction of the various parts of the BN model. The procedures are useful as it allows for maintaining consistency throughout the process and offers an element of confidence to the model. The procedures varying depending on the context of the model and level of data available. The methodology for constructing the $\mathrm{BN}$ is adapted from previous research in Loughney \& Wang (2017) and Loughney et al. (2018) (Fenton \& Neil, 2013) (Loughney \& Wang, 2017) (Loughney, et al., 2018).

\subsection{Establish the domain and definition}

This involves putting boundaries in place for the model. In this analysis the domain is to be defined as a module on a large offshore installation. The model begins with an initial component failure and tracks the cause and effect relationship of this failure on various other components and systems. The model ends with outlined consequences. The objective of the model involves stating what results are expected to be achieved from the model. For the model in this research the focus is on the interaction of the components and their probability of occurrence.

\subsection{Identify the set of variables relative to the problem}

This involves filtering possible parameters that are relevant to the description and objective. For the model the initial variables were devised utilizing a sequence of events diagram. This sequence of events diagram represents the steps of various events with their order and causality. The events in the diagram are connected with arcs and arrows. This allows for a straightforward transition to a BN.

\subsection{Form nodes and arcs for the $B N$}

The events and consequences in the sequence of events are translated to corresponding parent and child nodes in the Bayesian Network. The sequence of events, however, is basic and the arcs do not directly translate to the BN. The nodes can
3

be expressed as positive or negative. The causality between the events is translated to corresponding Conditional Probability Tables (CPTs). Once the relevant nodes are identified, they are input into a BN software package, HuginResearcher, and connected. This entails referring to the sequence of events from the initial failure to determine the most effective way of connecting the nodes together. The network is reviewed to ensure that there are no missing factors.

\subsection{Data acquisition and analysis}

Primarily, data is sought from various sources including: industrial \& academic publications, offshore risk assessment projects, as well as databases such as; the Offshore Reliability Database (OREDA), HSE and the International Association of Oil and Gas Producers database (OGP). However, should data not be widely available or the CPT for a node be much too large to construct utilizing data from the outlined sources, then methods of Boolean logic shall be applied. In this research that method is a Noisy-Or gate or a Noisy-AND gate (HSE, 2014) (HSE, 2008) (HSE, 2012) (Lloyds Register, 2016) (OGP, 2010) (Atkins, 2008) (OREDA, 2009).

A Noisy-Or gate is convenient for describing a class of uncertain relationships in Bayesian networks. This generalization is a useful modeling aid and in this research the Noisy-OR model is applied to one type of situation or connection in the BN. In these connections or situations at least one of the parent nodes $X_{i}$ must be in a positive state in order for the child node $\mathrm{Y}$ to have a chance, $P_{i}$, of being in a positive state. Furthermore, any combination of positive parent nodes can result in a positive child node with each combination potentially resulting in a different probability, $P_{i}$. For example, it is difficult to determine the CPT for the node Fault Detection \& Shutdown" so Noisy-OR is applied. In this case if either of the parent nodes ("Overload" or "Potential for Overspeed") are positive, i.e. in the state "Yes", then the Child node will also be in the positive state "Yes". Table 1 shows a brief example of this relationship where 1 represents a node in a positive state and $P_{i}$ represents the probability of the child node (Srinivas, 1993) (Vomlel, 2015).

Table 1. Example of a Noisy-OR truth table

\begin{tabular}{lll}
\hline \multicolumn{2}{l}{ Parent } & Child \\
$\mathrm{X}_{\mathrm{A}}$ & $\mathrm{X}_{\mathrm{B}}$ & $\mathrm{Y}$ \\
\hline 0 & 0 & 0 \\
1 & 0 & $1 \times P_{1}$ \\
0 & 1 & $1 \times P_{2}$ \\
1 & 1 & $1 \times P_{(1,2)}$
\end{tabular}

In the case of a Noisy-AND gate all of the parent nodes must be in a positive state for the child node to have a chance of being in a positive state as shown in Table 2 . In essence the only conjunctive effect of the parent node is shown by Eq. 1 .

$$
P\left(Y \mid X_{A}, X_{B}\right)=\left\{1 \text { if } X_{A}=x_{1} \text { and } X_{B}=x_{B} \text {, otherwise } 0\right\} \text { (1) }
$$

An example of a Noisy-AND gate can be seen in the node "Ignition Source". In this case the an ignition source would only be present if the parent nodes "Fault Detection \& Shutdown" and "Switchboard Overload" are in the States "No" and "Yes" Respectively. This is demonstrated by Table 2 . In this case the state "Yes" is represented by 1 and the state "No" is represented by 0 (Matellini, 2012) (Matellini, et al., 2013).

Table 2. Example of a Noisy-AND truth table

\begin{tabular}{lll}
\hline \multicolumn{2}{l}{ Parent } & Child \\
$\mathrm{X}_{\mathrm{A}}$ & $\mathrm{X}_{\mathrm{B}}$ & $\mathrm{Y}$ \\
\hline 0 & 0 & 0 \\
1 & 0 & 0 \\
0 & 1 & $1 \times P_{(1,2)}$ \\
1 & 1 & 0 \\
\hline
\end{tabular}

\subsection{Analysis of $\mathrm{BN}$ model}

This step concerns itself with the analysis of the BN model using Bayesian Inference. The probability of failure on demand of the operation is obtained by forward analysis. The posterior probabilities of the influencing factors can be calculated 
Loughney, S., Wang, J. \& Matellini, D. B.

through backward analysis, given some evidence entered into the model. The propagation of the $\mathrm{BN}$ is conducted using HuginResearcher. The results of the analysis provide useful information in handling the effect of one failure on multiple components and systems.

\subsection{Partial validation of the BN Model}

Validation is a key aspect of the methodology as it provides a reasonable amount of confidence to the results of the model. In carrying out a full validation of the model, the parameters should be closely monitored for a given period of time. For modelling a specific failure within an electrical generator, this exercise is not practical. In current work and literature, there is a three axiom based validation procedure, which is used for partial validation of the proposed $\mathrm{BN}$ model. The three axioms to be satisfied are as follows (Jones, et al., 2010) (Ashrafi, et al., 2017) (Fenton \& Neil, 2013):

- Axiom i:

A small increase or decrease in the prior subjective probabilities of each parent node should certainly result in the effect of a relative increase or decrease of the posterior probabilities of the child node.

\section{- Axiom ii:}

Given the variation of subjective probability distributions of each parent node, its influence magnitude to the child node should be kept consistent.

\section{- Axiom iii:}

The total influence magnitudes of the combination of the probability variations from " $x$ " attributes (evidence) on the values should always be greater than that from the set of " $x-y$ " $(\mathrm{y} \in \mathrm{x})$ attributes.

The methodology outlined in section 3 will be demonstrated in the Case Study in section 4.

\section{Cast Study}

\subsection{Establishing the domain and definition}

In order to demonstrate the proposed methodology a case study is used to evaluate of the effects overspeed and overload have on a gas turbine generator, particularly the $\mathrm{HC}$ release and ignition consequences. The electrical generation unit is considered to be of a generic layout for electrical generation on a large platform. The generator consists of a primary alternator, driven by a gas turbine. Located after the alternator is the exciter. The alternator rotor and shaft are forged in one piece with the exciter coupled on to one end. The opposite end of the shaft is coupled to the turbine drive shaft, which has an approximate operating speed of 3,600 rpm. The main shaft is supported by two main bearings, housed in pedestals, on stools on the baseplate. One bearing is situated between the turbine and the alternator and the other between the alternator and the exciter. Furthermore the combination of a HC and an electrical ignition source are considered feasible in this situation as the model, as with previous BN models produced in literature (Loughney \& Wang (2017) and Loughney et al. (2018)), is based upon the layout of the Thistle Alpha Platform in the North Sea. It can be seen from Figure 1 that the HC containment and the potential sources of electrical ignition are in close proximity. The module housing the switchboard and transformers is located directly above the three adjacent modules housing the

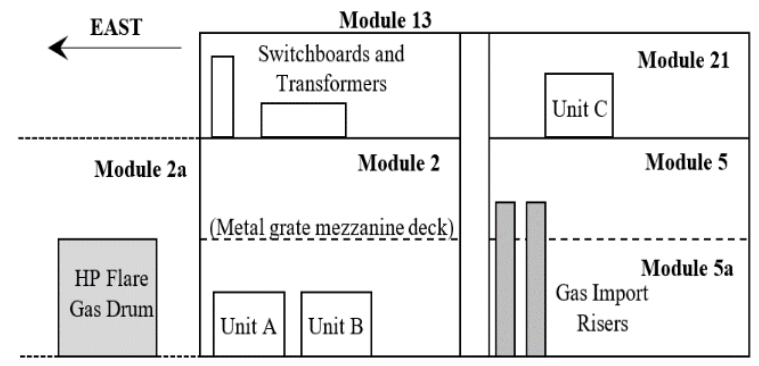

Figure 1. Northern view of the thistle Alpha Platform showing the location of key equipment
4

HP (High Pressure) gas flare drum, the generators and the gas import risers. Units A and B are the primary generator sets, while Unit $\mathrm{C}$ is the emergency generator. This research focuses on the mina generator sets (RMRI Plc., 2009).

In order to establish the domain and definition of the model, some assumptions are made. These assumptions are as follows:

- The model has been built for the situation where the offshore platform contains no crew and hence does not consider fatalities. There are two key reasons and they relate to the purpose of the dynamic risk assessment model. Firstly, the BN model can be applied an NUI (Normally Unattended Installation), where humans are not present on the platform for large periods of time, and are monitored from other platforms or onshore. Secondly, the BN can be applied to manned installations but where remote monitoring can be utilized to remove personnel from hazardous and dangerous situations and locations. Hence fatalities are not part of the initial model.

- The models purpose is to demonstrate that the cause and effect relationships between offshore failure modes, systems and components can be modelled effectively utilizing the methodology stated in section 3 .

- There are many component failures that can have an effect on the outcomes of the stated events, however, the BN model presented is part of a series of development cases. Hence, the cause and effects of a finite number of component failures and consequences are analyzed, to show that the model is valid before expansion to include crossovers of other scenarios.

- When the node "Fault Detection \& shutdown" is in the state "Yes", the relevant sensors have detected either overspeed or a current overload and the turbine and generator are shutdown. Having the barriers and fail safe in node serves to reduce the complexity of the model. Once the model is expanded with other situations, the barriers are to be modelled as a separate mitigation stage.

- In the case of "Gas Import Riser Impact" it is possible for the for the turbine blades of generator Unit B on the Thistle Alpha Platform to impact the riser in Module 5a. The location of which is shown in Figure 1.

- $\quad$ The HP Flare Drum outlined in the Node "HP Flare Drum Impact" is located in an adjacent module this impact is considered in the even the exciter detaches. The energy required to uproot and move the mass associated with the exciter is sufficient to cause the detached exciter to penetrate the module wall and damage adjacent $\mathrm{HC}$ containment.

\subsection{Identifying the set of variables}

The variables are identified based upon a number of control and electrical failures. Should there be a failure in the control system or a sudden loss of load, the turbine could potentially run overspeed, if the faults are not detected and the turbine shutdown. This would cause the main shaft to become unbalanced causing potential damage to certain components such as, the retaining rings or the bearings. Given the extreme tolerances' within the generator construction, the unbalanced shaft could also cause damage to other areas of the equipment, such as: the turbine blades and the exciter. (RMRI Plc., 2009). From this the most likely point of failure within the turbine is the turbine blades shearing. Multiple blade failure could lead to the turbine casing not fully containing the turbine blade debris. This situation has been analyzed by Loughney \& Wang (2017). This would result in turbine blades being expelled through the turbine casing as high velocity projectiles. Continually, the violent shaft vibrations and misalignment could have a severe impact on the exciter and may result in the exciter, weighing approximately one metric ton, becoming detached from the main shaft. Some catastrophic failures have resulted in the exciter breaking up and some have had the exciter remain mostly intact (RMRI Plc., 2009) (U.S. Nuclear Regulatory Commission, 2008).

Regarding the event of an electrical ignition source being present, the variables are defined from literature. In this case the failures are associated with a short-circuit event, and a failure in 
Loughney, S., Wang, J. \& Matellini, D. B.

the voltage control, both of which are outlines in Section 2.2. From here the event escalates in conjunction with multiple literature sources. There is an overload to the switchboard via a circuit breaker. The probability of a circuit breaker activating and the turbine shutting down is also included in the "Fault Detection \& Shutdown Node". In the event that the circuit breaker fails there is a possibility of an electrical ignition source. This event is encapsulated by the node "Ignition Source" and considers the probability of an arc-flash and extreme temperatures in wiring. These temperatures can easily exceed the flash point of the gas in both $\mathrm{HC}$ containment units in this BN model.

\subsection{Forming the $B N$}

The BN model structure is demonstrated in Figure 2, along with the marginal probabilities of the nodes. Table 3 outlines the abbreviations used in the $\mathrm{BN}$ and in the Analysis. The BN follows the sequence of events of the identified variables and events. The model consists of 17 nodes and all contain the states "Yes" or "No", with the exception of two. The node IG utilizes two states relating to the immediate or delayed ignition from the HP flare drum failure, two states relating to the immediate or delayed ignition of the gas from the import riser and a state where there is no ignition. These states are as follows: "Immediate (HP Tank)", "Delayed (HP Tank", "Immediate (Riser)", "Immediate (Riser)", "Delayed (Riser)" and "None". The node FEXP has three states, these are "Fire", "Explosion", and "None". This node outlines the occurrence probability of either a fire or an explosion.

Table 3. Abbreviations used in the BN model and the analysis.

\begin{tabular}{ll}
\hline Abbreviation & Node Name \\
\hline CSF & Control System Failure \\
LL & Loss of Load \\
VCF & Voltage Control Failure \\
SC & Short Circuit \\
PFO & Potential For Overspeed \\
PSS & Power Surge to Switchboard \\
SBO & Switchboard Overload \\
FD\&S & Fault Detection \& Shutdown \\
IGS & Ignition Source \\
TRO & Turbine Runs Overspeed \\
FDS & Fault Detection \& Shutdown \\
TRO & Turbine Runs Overspeed \\
TBX & Turbine Blades Expelled \\
ED & Exciter Detaches \\
GIR & Gas Import Riser Impact \\
HPF & HP Flare Drum Impact \\
HCR & HC Release \\
IG & Immediate or Delayed Ignition \\
IG - I-Tank & IG - Immediate - Tank \\
IG - D-Tank & IG - Delayed Tank \\
IG - I-Riser & IG - Immediate Riser \\
IG - D- Riser & IG - Delayed Riser \\
FEXP & Fire or Explosion \\
F & Fire \\
EXP & Explosion \\
\hline
\end{tabular}

\subsection{Data acquisition and analysis}

It is important to note that the numerical results of the model are not significant in terms of being absolute, but rather to serve to demonstrate the practicability of the model. Once a full set of verified data is fed into the model, the confidence level associated with planning and decision making under uncertainty will improve.

To complete the CPTs within a BN, certain data and knowledge is required regarding each specific node. For some nodes data is limited or not available. For cases where there is an absence of hard data, CPTs must be completed through subjective reasoning. As previously stated in Section 3.4, a Noisy-OR gate and a Noisy-AND gate have been applied to complete CPTs in the $\mathrm{BN}$.

\subsection{Analysis of the $B N$}

The $\mathrm{Bn}$ has been used to analyze a number of possible realworld scenarios. The Hugin software allows for evidence to be
5

insert-ed to all nodes within the network in its "Run Mode" function. This evidence is to the degree of $100 \%$ in a given state of a node. It is the posterior probabilities that are of interest and are computed given particular evidence of specific nodes. All values in the analysis are percentage probabilities.

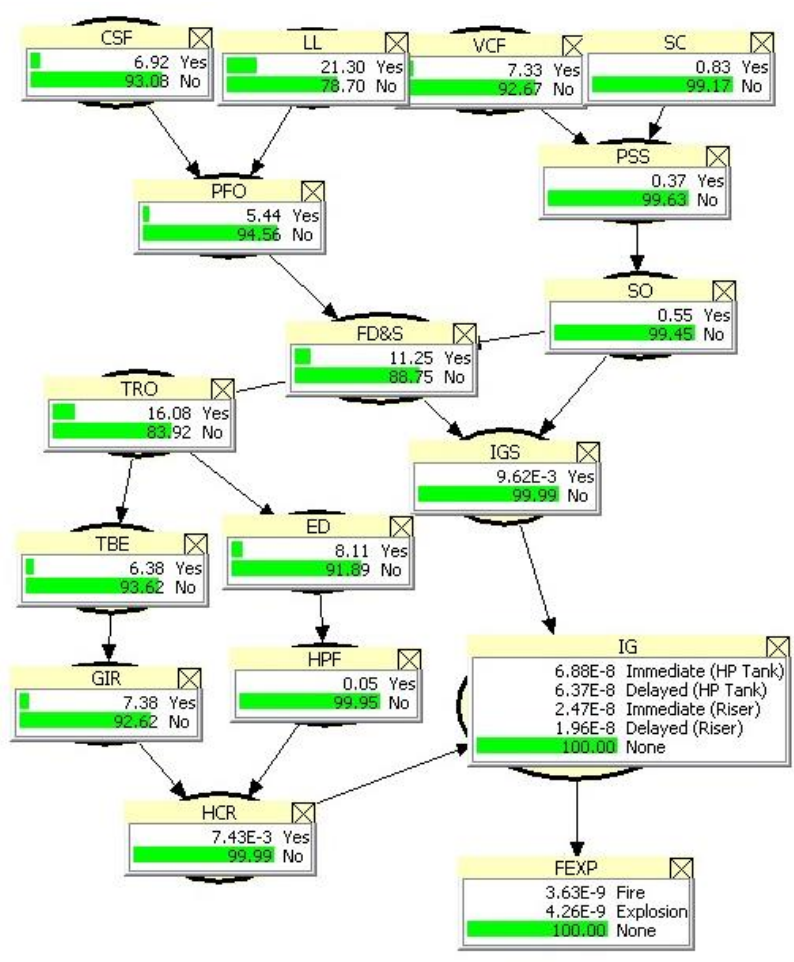

Figure 2. BN model structure along with the marginal probabilities of each node.

\subsubsection{Test Case 1}

This case study demonstrates the effects of the root nodes "CSF", "LL", "VCF" and "SC" on the BN model. This analysis shall focus on the node "FD\&S" and the potential for ignition, demonstrating the role of the incident prevention measures. The analysis is to be split and will focus on "CSF" and "LL" together and "VCF" and "SC" together. Table 4 shows the effect of "CSF" and "LL" on key nodes and states in the BN. References to the abbreviations can be found in Table 3. Each test case in the analysis will show focus nodes and states with no evidence inserted into the hypothesis nodes. In Table 4, these hypothesis nodes are "CSF" and "LL" evidence is then inserted into a given state in the hypothesis node and the posterior probabilities of the focus nodes are analyzed.

Table 4. Effects of the root nodes "CSF" and "LL" both separately and cumulatively.

\begin{tabular}{lllll}
\hline $\begin{array}{l}\text { Focus } \\
\text { Nodes }\end{array}$ & $\begin{array}{l}\text { No } \\
\text { Evidence }\end{array}$ & $\begin{array}{l}\text { CSF-Yes } \\
\text { LL-Yes }\end{array}$ & $\begin{array}{l}\text { FCS + LL- } \\
\text { Yes }\end{array}$ \\
\hline PFO & 5.44 & 27.00 & 19.60 & 41.70 \\
FD\&S & 11.25 & 24.95 & 20.25 & 33.95 \\
TRO & 16.09 & 13.6 & 14.45 & 11.97 \\
HCR & 0.00743 & 0.00724 & 0.0073 & 0.00711 \\
IG-I-Tank & $6.88 \mathrm{E}-08$ & $5.89 \mathrm{E}-08$ & $6.23 \mathrm{E}-08$ & $5.24 \mathrm{E}-08$ \\
IG-D-Tank & $6.37 \mathrm{E}-08$ & $5.46 \mathrm{E}-08$ & $5.77 \mathrm{E}-08$ & $4.85 \mathrm{E}-08$ \\
IG-I-Riser & $2.47 \mathrm{E}-08$ & $2.12 \mathrm{E}-08$ & $2.24 \mathrm{E}-08$ & $1.88 \mathrm{E}-08$ \\
IG-D- Riser & $1.96 \mathrm{E}-08$ & $1.68 \mathrm{E}-08$ & $1.78 \mathrm{E}-08$ & $1.49 \mathrm{E}-08$ \\
\hline
\end{tabular}

From Table 4 it can be seen that "CSF" has a greater effect on the system than "LL". Similarly, both nodes demonstrate a large cumulative effect on nodes "PFO" and FD\&S". However, it can be seen that the posterior probabilities of overspeed (TRO) or $\mathrm{HC}$ release (HCR) decrease when evidence is inserted into the root nodes. This demonstrates that the barrier node "FD\&S" is operating in the BN as expected. It is assumed in this analysis that the barriers mitigating against incidents would operate as expected. Therefore, in the event of an increased probability of initial faults, there is an increased probability in the detection 
Loughney, S., Wang, J. \& Matellini, D. B. and prevention of further escalation. What is also apparent from the analysis is the very negligible effect on the probabilities of immediate or delayed ignition from either the gas riser or the HP tank. This is due to the system again detecting a fault and halting the process. Thus, reducing the probability of an overspeed event. Similarly, this section of the BN model has no effect on the probability of an ignition source being present. Hence, any incidents would only result in a $\mathrm{HC}$ release and not an ignition incident.

Table 5 demonstrates the effect of "VCF" and "SC" on key nodes and states in the BN.

Table 5. Effects of the root nodes "VCF" and "SC" both separately and cumulatively.
6

probability of an ignition source. This is because there is a small probability the cabling from the generator to the circuit breaker can achieve very high temperatures before the circuit breaker activates. This wiring has the potential to reach high temperatures and damage the insulation around the cabling. As stated in Section 2, it is possible for the damaged insulation around the cable to burn and produce flammable gases. Hence there is still a small in crease in the chance of an ignition source being present. This also demonstrates that overspeed and overload sections are somewhat independent as the probability of ignition only increases when there is an overload event.

\subsubsection{Test Case 3}

Test case 3 demonstrates the individual and cumulative effect of a $\mathrm{HC}$ release and the presence of an Ignition source. This

\begin{tabular}{llll}
\hline & & & \\
Focus Nodes & No Evidence & VCF- Yes & SC-Yes \\
\hline PSS & 0.37 & 4.99 & 0.93 \\
SBO & 0.55 & 1.21 & 0.63 \\
FDS & 11.25 & 11.67 & 11.3 \\
IGS & 0.00926 & 0.02 & 0.0001 \\
HCR & 0.00743 & 0.00742 & 0.00743 \\
IG-I-Tank & $6.88 \mathrm{E}-08$ & $1.51 \mathrm{E}-07$ & $7.88 \mathrm{E}-08$ \\
IG-D-Tank & $6.37 \mathrm{E}-08$ & $1.40 \mathrm{E}-07$ & $7.30 \mathrm{E}-08$ \\
IG-I-Riser & $2.47 \mathrm{E}-08$ & $5.42 \mathrm{E}-08$ & $2.83 \mathrm{E}-08$ \\
IG-D-Riser & $1.96 \mathrm{E}-08$ & $4.30 \mathrm{E}-08$ & $2.25 \mathrm{E}-08$ \\
\hline
\end{tabular}
$\mathrm{CF}+$ scenario assumes that either an overspeed event or an overload Yes event has occurred and either one or both is not detected. Table $5.53 \quad 7$ demonstrates the posterior probabilities of each ignition 1.29 scenario and the potential fire and explosion consequences.

11.72

0.02

Table 7. Individual and cumulative effects of a $\mathrm{HC}$ release and $1.61 \mathrm{E}-07$ an ignition source.

$5.77 \mathrm{E}-08$ $4.58 \mathrm{E}-08$

It can be seen that "VCF" has a much greater effect on the child nodes when compared to "SC". Similarly, the effect from either node on the child nodes is not very large. What can also be seen is the effect of node "FD\&S" on the BN as seen in Table 4. Furthermore, this section of the $\mathrm{BN}$ should have a negligible effect on the probability of $\mathrm{HC}$ release. This is proven by the posterior probabilities in table 5, where there is almost zero change in the posterior probability of a $\mathrm{HC}$ release. What is apparent is the increase change in the probability of an ignition. In Table 4 the probability of ignition does increase past $10^{-8}$, yet in Table 5 a greater change, by comparison, can be seen as the probability increases to $10^{-7}$ in some cases. This demonstrates that even without a $\mathrm{HC}$ release, a small increase in an ignition source being present. This demonstrates that an ignition source may have a greater effect on the probability of fire or explosion than a $\mathrm{HC}$ release, dispute the fact that both are required to cause either of the consequences.

\subsubsection{Test case 2}

Test case 2 shall demonstrate the effects of potential overspeed and overload events. In this case the likelihood of an ignition source and a $\mathrm{HC}$ release being present are analyzed due to events that can initiate either or both consequences. Table 6 demonstrates the posterior probabilities of certain focus nodes given individual and cumulative overspeed and overload events.

Table 6. Individual and cumulative effects of potential overspeed and overload events on the $\mathrm{BN}$.

\begin{tabular}{lllll}
\hline $\begin{array}{l}\text { Focus } \\
\text { nodes }\end{array}$ & $\begin{array}{l}\text { No } \\
\text { Evidence }\end{array}$ & PFO-Yes & SBO-Yes & $\begin{array}{l}\text { PFO } \\
\text { SBO-Yes }\end{array}$ \\
\hline FDS & 11.25 & 71.31 & 75.10 & 90.80 \\
TRO & 16.08 & 5.20 & 4.51 & 1.67 \\
TBX & 6.38 & 2.12 & 1.74 & 0.74 \\
ED & 8.11 & 2.67 & 2.33 & 0.10 \\
GIR & 7.38 & 6.58 & 6.53 & 6.32 \\
HPF & 0.05 & 0.02 & 0.02 & 0.01 \\
IGS & 0.00962 & 0.00355 & 1.74 & 0.64 \\
HCR & $7.43 \mathrm{E}-03$ & $6.60 \mathrm{E}-03$ & $6.55 \mathrm{E}-05$ & $6.33 \mathrm{E}-03$ \\
IG-I-Tank & $6.88 \mathrm{E}-08$ & $2.54 \mathrm{E}-06$ & $1.25 \mathrm{E}-07$ & $4.61 \mathrm{E}-06$ \\
IG-D-Tank & $6.37 \mathrm{E}-08$ & $2.35 \mathrm{E}-08$ & $1.15 \mathrm{E}-07$ & $4.27 \mathrm{E}-06$ \\
IG-I-Riser & $2.47 \mathrm{E}-08$ & $9.13 \mathrm{E}-09$ & $4.48 \mathrm{E}-07$ & $1.66 \mathrm{E}-06$ \\
IG-D- Riser & $1.96 \mathrm{E}-08$ & $7.25 \mathrm{E}-09$ & $3.55 \mathrm{E}-08$ & $1.31 \mathrm{E}-06$ \\
\hline
\end{tabular}

It can be seen from Table 6 that the "FD\&S" node is greatly affected by an overspeed or overload event occurring. The assumption again is that the detection system operates as designed. Hence the $90.8 \%$ probability of a fault detection and shutdown given both an overspeed and overload event occur. This can also be seen by the decrease in the probability of a HC release occurring, due to the reduced probability of the "TRO" node. However, what can be seen is an increase in the

\begin{tabular}{lllll}
\hline $\begin{array}{l}\text { Focus } \\
\text { nodes }\end{array}$ & $\begin{array}{l}\text { No } \\
\text { Evidence }\end{array}$ & HCR-Yes & IGS-Yes & $\begin{array}{l}\text { IGS }+ \\
\text { HCR- }\end{array}$ \\
\hline IG-I-Tank & $6.88 \mathrm{E}-08$ & $9.27 \mathrm{E}-04$ & $7.16 \mathrm{E}-04$ & 9.44 \\
IG-D-Tank & $6.37 \mathrm{E}-08$ & $8.58 \mathrm{E}-04$ & $6.63 \mathrm{E}-04$ & 8.74 \\
IG-I-Riser & $2.47 \mathrm{E}-08$ & $3.33 \mathrm{E}-04$ & $2.57 \mathrm{E}-04$ & 3.39 \\
IG-D- Riser & $1.96 \mathrm{E}-08$ & $2.64 \mathrm{E}-04$ & $2.04 \mathrm{E}-04$ & 2.69 \\
Fire & $3.63 \mathrm{E}-09$ & $4.88 \mathrm{E}-05$ & $3.77 \mathrm{E}-05$ & 0.50 \\
Explosion & $4.26 \mathrm{E}-09$ & $5.74 \mathrm{E}-05$ & $4.43 \mathrm{E}-05$ & 0.58 \\
\hline
\end{tabular}

Form Table 7 it can be seen that the probability of an ignition, and subsequently a fire or explosion consequence, increases when either a $\mathrm{HC}$ release has occurred, or an ignition source is present. This provides some evidence that the BN further operates as intended. In order for an ignition incident to occur there must be a source of ignition and a fuel source. Similarly, proportions. Therefore, the probability of an ignition event is still relatively low when only one event of a release or an ignition source occurs. However, when both events are observed, the probabilities of any type of ignition, with either the riser or HP tank as the source, increases by a factor of $10^{4}$. It can be seen that an ignition given a HP tank release is greater than that of the gas riser. This is because of the proximity of the release and the ignition source. In the event the gas riser is impacted by the turbine blades of Unit B, there are enough barriers to divert the release away from the ignition source, assuming the ignition source is in module 13 (See Figure 1). Similarly, in order for the HP tank to be impacted, an exciter must detach and penetrate the wall of module 2 . This leaves a large section of the wall open to the potential release from the HP. Furthermore, the HP tank stores natural gas at a much higher pressure than that of the import riser, therefore the expansion after release will be much greater. Continually, the hole size produced by an exciter impacting the tank will also be much greater than the holes produce $b$ y the turbine blades impacting the gas rise. Therefore, an ignition of the $\mathrm{HC}$ in the HP tank is much more likely.

Finally, given that both events occur there is an increase in the probability of either a fire or an explosion also by a factor of $10^{4}$. The probability of an explosion is slightly higher dur to the fact that that explosions occur after a delayed ignition. Similarly, the proximity to the ignition source of the HC releases would suggest that a delayed ignition is more likely. However, given that the gas expansion from both sources, particularly from the HP tank, an immediate ignition is just as likely. Furthermore, the nature of the ignition source, i.e. an arc flash, is instantaneous. Therefore, the gas in the vicinity of the flash would ignite immediately and is more likely to cause a fire. That said, further testing is required in the time domain to more accurately demonstrate the fire and explosion consequences and map the $\mathrm{HC}$ releases over time at various release rates. the fuel source must be in an oxygen mixture of the correct 
Loughney, S., Wang, J. \& Matellini, D. B. 4.5.4 Test case 4

To provide further verification of the $\mathrm{BN}$ model it is important to demonstrate the effects of inserting evidence as a consequence and observing the effects on prior nodes. The node in question in this test case is the "FEXP" node. Where evidence is inserted into the states "Fire" and "Explosion". Table 8 demonstrates the effect of the prior probabilities sin the $\mathrm{BN}$ when $100 \%$ evidence is inserted into the states "Fire" and "Explosion".

Table 8. Effect of $100 \%$ "Fire" and "Explosion" on the prior probabilities of key nodes in the $\mathrm{BN}$.

\begin{tabular}{llll}
\hline Focus nodes & $\begin{array}{l}\text { No } \\
\text { Evidence }\end{array}$ & Fire & EXP \\
\hline PSS & 0.37 & 9.90 & 9.90 \\
SBO & 0.55 & 100.00 & 100.00 \\
FDS & 11.25 & 0.00 & 0.00 \\
TRO & 16.08 & 32.96 & 32.96 \\
TBX & 6.39 & 23.89 & 23.89 \\
ED & 8.11 & 16.79 & 16.79 \\
GIR & 7.38 & 99.51 & 99.51 \\
HPF & 0.05 & 0.66 & 0.66 \\
IGS & 0.01 & 100.00 & 100.00 \\
HCR & 0.007 & 100.00 & 100.00 \\
IG-I-Tank & $6.88 \mathrm{E}-08$ & 64.15 & 0.00 \\
IG-D-Tank & $6.37 \mathrm{E}-08$ & 25.19 & 91.35 \\
IG-I-Riser & $2.47 \mathrm{E}-08$ & 8.27 & 0.00 \\
IG-D-Riser & $1.96 \mathrm{E}-08$ & 2.39 & 8.65 \\
\hline
\end{tabular}

It can be seen from Table 8 that when the "Fire" and "Explosion" states are observed individually, four nodes demonstrate $100 \%$ or $0.00 \%$ occurrence. The nodes that demonstrate $100 \%$ occurrence are "SBO", "IGS" and "HCR". This is in line with previous analyses and hypotheses whereby a fire or explosion requires and ignition source and a $\mathrm{HC}$ release. It also make sense that the node "SBO" is at $100 \%$ as in this $\mathrm{BN}$ an overload is required for the ignition source to occur. However, there are a couple of situations that can cause a $\mathrm{HC}$ release. In this case there is a $99.51 \%$ chance that the HCR is caused by "GIR" and a $0.66 \%$ chance that it is "HPF". This also makes sense as a riser impact is comparatively much more likely than a HP tank impact. The node that demonstrates a $0 \%$ chance of occurrence is "FD\&D" which is also in conjunction with previous statements as the consequences will only occur if faults are not detected. Furthermore, when an Explosion occurs, both "IG-I" are at $0 \%$, further demonstrating that a a delayed ignition is required.

\subsubsection{Partial Validation}

For partial validation of the model, it should satisfy the three axioms stated in Section 3.6. Given the demonstrated analysis in Section 4.5 and the behavior of the prior and posterior probabilities when subjected to different situations, it can be said that the BN model satisfies the outlined axioms. Therefore, some partial validation can be given to the model.

\section{Conclusions}

The BN model presented in this research demonstrates the effect that several initial failures have on a potential $\mathrm{HC}$ release and potential electrical ignition source along with the potential fire and explosion consequences that can occur. These consequences are equally important for offshore platform operators due to the additional HSE regulations within Safety Cases regarding hazards to the environment in any instance. Therefore, if there is a $\mathrm{HC}$ release without ignition, it poses a large issue for operators and duty holders given that the release is undetected.

The analysis presented in the four test cases clearly demonstrates the vital role that the mitigating barriers play in preventing severe. The BN model also clearly demonstrates that it can provide an effective and applicable method of determining the likelihood of various events under uncertainty, and more importantly show increased uses as a dynamic risk
7

assessment tool. This is especially applicable in monitoring offshore areas where personnel are not normally present.

\section{Acknowledgements}

This research was supported by Liverpool John Moores University. The authors also thank the EU for its financial support under European Commission funded project RESET (2017-2020).

\section{References}

Abimdola, M., Khan, F. \& Khakzad, N., 2014. Dynamic safety risk analysis of offshore drilling. journal of Loss Prevention in Process Industries, Volume 30, pp. 74-85.

Almasi, A., 2011. Specifying Gas Turbines. Chemical Engineering, $118(5)$, pp. $52-59$.

Ashrafi, M., Davoudpour, H. \& Khodakarami, V., 2017. A Bayesian Network to Ease Knowledge Acquisition of Causal Dependence in CREAM: Application of Recursive NoisyOR Gates. Quality and Reliability Engineering International, Volume 33, pp. 479-491.

Atkins, 2008. Thistle Alpha 2008 Quantitative Risk Analysis, : Atkins.

Boeman, K., 2013. Electrical Safety Growing Focus for Oil, Gas $\begin{array}{lll}\text { Industry } & \text { (RigZone). } \\ \text { Available } & \text { [Online] }\end{array}$ Available https://www.rigzone.com/news/oil_gas/a/127032/electrical safety_growing_focus_for_oil_gas_industry/?all=hg2 [Accessed January 2019].

Chacartegui, R., Sanchez, D., Munoz, A. \& Sanchez, T., 2011. Real time simulation of medium size gas turbines. Energy Conversion and Management, Volume 52, pp. 713 - 724.

CLarck, C. G., 2018. The Basics of Arc Flash (General Engineering). [Online]

Available

https://apps geindustrial com/publibrary/checkout/ArcFlas

h4?TNR=White\%20Papers|ArcFlash4|PDF

[Accessed January 2019].

Courty, L. \& Garo, J. P., 2017. External heating of electrical cables and auto-ignition investigation. Journal of Hazardous Materials, Volume 321, pp. 528-536.

Fenton, N. \& Neil, M., 2013. Risk Assessment and Decision Analysis with Bayesian Networks. 1st ed. : Taylor \& Francis Group.

Fetenant, A., Shafipour, G. \& Ghanatir, F., 2012. Reliability redundancy optimization for optimal designing in gas turbines' overspeed protction using elitism box-muller harmony search algorithm. Journal of Theoretical and Applied Iformation Technology, 46(2), pp. 991 -1000.

Fisher, R. P., Stoliarov, S. I. \& Keller, M. R., 2015. A criterion for thermally-induced failure of electrical cable. Fire Safety Journal, Volume 72, pp. 33-39.

Herschberger, D., 2013. Pushin macines to the limit: transitioning to digital overspeed protection, Barrington: Control Engineerig - ProQuest.

HSE, 2008. Fire and explosion hazards in offshore gas turbines, London: the Health and Safety Executive.

HSE, 2012. Fire and explosion structural integrity assessment: Appendix 2 - Technical background note, London: the Health and Safety Executive.

HSE, H. a. S. E., 2006. Offshore Gas Turbines (and Major Driven Equipment) Integrity and Inspection Guidence Notes, Oxfordshire: ESR Technology Ltd..

HSE, H. a. S. E., 2014. Statistics - Offshore Hydrocarbon Releases 1992 - $2015 . \quad$ [Online] Available at: http://www.hse.gov.uk/offshore/statistics.htm [Accessed December 2015].

Jones, B., Jenkinson, I., Yang, Z. \& Wang, J., 2010. The Use of Bayesian Network Modelling for Maintenance Planning in a Manufacturing Inductry. Reliability Engineering and System Safety, Volume 95, pp. 267-277.

Lee, K., 2018. Electrical Power in the Offshore Environment (Charles Taylor Adjusting). [Online] Available at: http://www.asiaoec.com/wpcontent/uploads/2017/11/Day-1-5-Electrical-Power-in-theOffshore-Environment-Keith-Lee.pdf [Accessed January 2019].

Lloyds Register, 2016. Ignition model parameters for objects intended for use in potentially explosive atmospheres. In: Modelling of ignition sources on offshore oil and gas facilities MISOF (Report No.: 106364/R1). Bergen, Norway: Lloyds Register, pp. 30 - 59.

Loughney, S. \& Wang, J., 2017. Bayesian network modelling of an offshore electrical generation system for applications within 
Loughney, S., Wang, J. \& Matellini, D. B.

an asset integrity case for normally unattended offshore installatons. Proc. IMechE Part M: J. Engineering for the Maritime Environment, 232(4), pp. 402-420.

Loughney, S., Wang, J. \& Matellini, D., 2018. Utilising bayesian networks to demonstrate the potential consequences of a fuel gas release from an offshore gas driven turbine. Proc. IMechE Part M: J. Engineering for the Maritime Environment, Volume Online, pp. 1-21.

Matellini, D. B. et al., 2013. A study of human reaction during the initial stages of a dwelling fire using a bayesian network model. Proc. IMechE Part O: Journal of Risk and Reliability, 227(2), pp. 207 - 221.

OGP, 2010. Risk assessment data directory - ignition probabilities, s.l.: International Associaton of Oil \& Gas Producers (Report No.: 434-6.1).

Onsite Energy, 2013. Short Circuit and Overload Protection Devices Within an Electrical System (Information Sheet \# 07). [Online]

Available at: https://cpower.com/PDF/InfoSheets/07.pdf [Accessed January 2019].

OREDA, 2009. Offshore Reliability-Data Handbook. Oslo: Det Norske Veritas Germanischer Lloyd.

Passalacqua, R. et al., 2013. Experimental characterisation of ITER electric cables in postulated fire scenarios. Fusion Engineering and Design, Volume 88, pp. 2650-2654.

Pawsey, L., Rajendran, D. J. \& Pachidis, V., 2018. Characterisation of turbine behavious for an engine overspeed predicton model. Aerospace and Technology, Volume 73, pp. 10-18.

Perera, L. P., Machado, M. M., Manguinho, D. A. P. \& Valland, A., 2016. System failures of offshore gas turbine engines in maintenance perspective. IFAC (International Federation of Automatic Control) - PapersOnLine, 49(28), pp. 280285.

Perera, L. P., Machado, M. M., Valland, A. \& Manguinho, D. A. P., 2015. Modelling of System Failures in Gas Turbine Engines on Offshore Platforms. IFAC, 48(6), pp. 194-199.

RMRI Plc., 2009. Assessment of Risks Associated with the Alternator Rotor End Cap Disintegration on the Thistle Alpha Platform. Manchester: Petrofac Facilities Management Ltd..

Shan-jun, M., Jun, Z., Dong, L. \& Hong-yin, C., 2013. Study on pyrolysis characteristics of cross-linked polyethylene material cable. Procedia Engineering, Volume 52, pp. 588592.

Srinivas, S., 1993. A generalization of the noisy-OR model. Proceedings of the Ninth Conference on Uncertainty in Artificial Intelligence (UAI1993), Volume UAI-P-1993PG-208-215, pp. 208 - 215.

U.S. Nuclear Regulatory Commission, 2008. Potential Generator Missiles- Generator Rotor Retaining Rings. Resolution of Generic Safety Issues, August.

Vomlel, J., 2015. Generalizations of the noisy-OR model. Kybernetika, 51(3), pp. 508-524.

Wang, X. et al., 2016. Ignition and flame propagation of externally heated electrical wires with electric currents. Fire Technology, Volume 52, pp. 533-546. 